\title{
Sequentiality of treatment in the rheumatoid arthritis drug programme in the years 2009-2014
}

Małgorzata Tłustochowicz ${ }^{1}$, Andrzej M. Śliwczyński²,3, Melania Brzozowska ${ }^{2,3}$, Zbigniew Teter ${ }^{3}$, Michał Marczak²

\author{
${ }^{1}$ Rheumatology Department, Military Medical Institute, Warsaw, Poland \\ ${ }^{2}$ Department of Quality, Procedures and Medical Standards, Medical University \\ of Lodz, Lodz, Poland \\ ${ }^{3}$ National Health Fund, Warsaw, Poland
}

Submitted: 29 December 2015

Accepted: 11 February 2016

Arch Med Sci 2018; 14, 3: 569-571

DOI: https://doi.org/10.5114/aoms.2016.58924

Copyright $\odot 2016$ Termedia \& Banach

\begin{abstract}
Approximately $1 \%$ of the population suffers from rheumatoid arthritis (RA) worldwide $(0.45 \%$ in Poland). The therapy consists of the use of disease-modifying antirheumatic drugs (DMARDs). Biologics are used in the form of the drug programme. Analysis of the NHF database demonstrated the sequence of conversion between drugs and time spent in a single treatment. In 2009, the patients would start the following treatments: adalimumab $5.8 \%$; etanercept $14.4 \%$; infliximab $23.1 \%$; leflunomide $53.6 \%$; rituximab $3 \%$. After the first year $16 \%$ of patients changed therapy or abstained, and in the second year this situation affected $65 \%$ of patients. The following percentages maintained the same treatment in the last 6 years: infliximab $4 \%$; adalimumab $15 \%$; etanercept $21 \%$; leflunomide on prescription was continued by $70 \%$. Patients remain too long on the same therapy when it is inefficient. Achieving remission or low disease activity (DAS28<2.6) should take place within 6 months of starting therapy.
\end{abstract}

Key words: biological drug, rheumatoid arthritis, sequentiality of treatment.

Rheumatoid arthritis (RA) is a chronic autoimmune inflammatory disease of unknown aetiology leading to injuries of joint structure and tissue surrounding the joints. Available data indicate that worldwide $1 \%$ of the population suffers from it (from $0.5 \%$ to $2 \% ; 0.45 \%$ in Poland) $[1,2]$. The studies indicate that the longevity of RA patients compared to the general population is 3 years shorter in the case of women and 7 years shorter in the case of men [3].

The diagnosis was established based on the criteria established by the American College of Rheumatology (ACR) in 1987, based on the clinical picture of the advanced stage of the disease, currently the common criteria of the European League Against Rheumatism (EULAR) and the $A C R$, which enable the diagnosis of its early forms [4]. The basis for the treatment consists of classical synthetic drugs which modify the course of the disease (methotrexate and leflunomide, in some cases sulfasalazine). In the case of their failure, the use of biological drugs which modify the course of the disease is recommended [5], adding them to the synthetic drugs, preferably methotrexate.

\author{
Corresponding author: \\ Andrzej M. Śliwczyński PhD \\ National Health Fund \\ 186 Grójecka St \\ 02-390 Warsaw, Poland \\ Phone: +48 604800718 \\ E-mail: andrzej.sliwczynski@ \\ nfz.gov.pl
}


Due to the very high price of biological drugs, this therapy in Poland is financed as part of a special procedure, called the drug programme (previously called the treatment programme). The programme indicates the method of patient therapy using specific molecules (drugs) with precisely established programme admittance and discharge criteria established first pursuant to the NICE recommendations of 2002, and currently to the latest EULAR recommendations $[6,7]$. The goal of the analysis is to establish the process of biological drug changes in RA patients which were admitted to the programme therapy in 2009.

The report databases of the public payer ( $\mathrm{Na}$ tional Health Fund) were analysed in order to identify a separate population of patients with rheumatoid arthritis (RA) who began their therapy under the drug therapy programme in 2009. The type of drug administered (active particle) to a given patient in the report data provided by healthcare providers was verified at yearly intervals (at the beginning of 2009 and subsequently at the beginning of each year, and at the beginning and at the end of 2014). During the period considered (2009-2014) the following drugs were financed under the drug therapy programme: le- flunomide (LEFL) (which was next moved in 2010 to the segment of pharmacies open to the public and became available on a medicinal prescription), adalimumab (ADAL), etanercept (ETAN), infliximab (INFL), rituximab (RITU), certolizumab (CERT), and golimumab (GOLI), which were successively included in the therapy. Based on the patient's individual identification number (the PESEL number), therapy lines with the drugs used in therapy and the switches between types of therapy were determined for individual patients.

The analysis resulted in report data for the RA drug programme therapy concerning 1167 patients who started the therapy in 2009 with drugs available at the time. Sixty-eight (5.8\%) patients started therapy with adalimumab; 168 (14.4\%) with etanercept; 270 (23.1\%) with infliximab; 35 (3\%) with rituximab; $53.6 \%$ (626) with leflunomide. During the first year the therapy with the same molecule was continued by: $80.9 \%$ of patients for adalimumab; $85.4 \%$ for etanercept; $84.1 \%$ for infliximab; $74.9 \%$ for leflunomide (Figure 1).

The highest frequency of therapy changes occurred for infliximab treatment; the number of patients who changed to another therapy was after the $1^{\text {st }}$ year $5 \%$, after the $2^{\text {nd }}$ year $32 \%$, after the $3^{\text {rd }}$



Figure 1. Number of patients who continue the therapy with the same drug by individual years

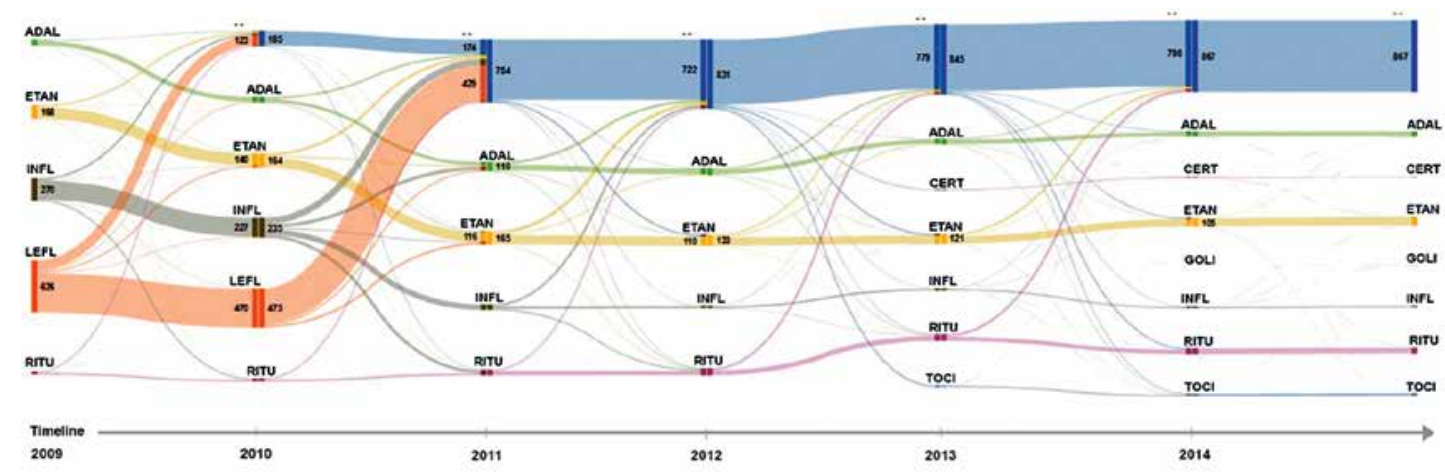

Figure 2. Sankey diagrams for changes of therapy using individual drugs for patients admitted for treatment in 2009 (for the period of 2009 to 2014)

ADAL - adalimumab, ETAN - etanercept, INFL - infliximab, LEFL - leflunomide, RITU - rituximab, TOCI - tocilizumab, GOLI - golimumab, CERT - certolizumab. 
year $80 \%$, after the $4^{\text {th }}$ year $91 \%$, after the $5^{\text {th }}$ year $94 \%$, and after the $6^{\text {th }}$ year $96 \%$ (average slope of patient loss curve over 6 years was $48 \%$ ). Four percent of the patients included in the treatment remained on therapy using the same molecule. Adalimumab had the second highest frequency of therapy changes, with the following patient loss over successive years of therapy: $1^{\text {st }}$ year $0 \%$; $2^{\text {nd }}$ year $31 \%$; $3^{\text {rd }}$ year $59 \%$; $4^{\text {th }}$ year $78 \% ; 5^{\text {th }}$ year $82 \%$; $6^{\text {th }}$ year $85 \%$. The continuation of adalimumab therapy after 6 years was observed in $15 \%$ of patients (average slope of patient loss curve over 6 years was 41\%). Etanercept therapy showed the lowest variability: $1^{\text {st }}$ year $2 \%$; $2^{\text {nd }}$ year $24 \%$; $3^{\text {rd }}$ year $36 \% ; 4^{\text {th }}$ year $67 \% ; 5^{\text {th }}$ year $71 \% ; 6^{\text {th }}$ year $79 \%$. The continuation of therapy after 6 years applied to $21 \%$ of patients (average slope of patient loss curve over 6 years was $41 \%$ ). The analysis of patient flows between therapies is presented in the figure (Figure 2). The tendency of changes of therapy and the large percentage of patients who end their therapy (understood as lack of continuation of therapy within the drug programme) can be observed.

Out of 1167 patients who started therapy in 2009, 186 persons (approx. 16\%) stopped/halted the therapy after the first year. During the next 2 years the number of stopped/interrupted therapies was already 754 persons (approx. 65\%). From this population which had finished/halted the therapy some patients returned to therapy with the same or a different molecule during the third year of observation. Legislative changes and moving leflunomide to the group of reimbursed pharmacy drugs has forced the end of this part of the programme, yet among the 626 patients treated with this molecule 441 continued therapy under out-patient care, purchasing the drug in the pharmacy.

In the current treatment recommendations established by EULAR the therapeutic goal of remission (or low activity of the disease in each patient) after 6 months of treatment (DAS28 below 2.6) was established. If the goal is not reached, the therapy should be modified regardless of the drug used. The anchor drug is methotrexate used in a dosage of 25-30 mg/week for a period of at least 2 months, and if its use fails it should be supplemented by another classical synthetic or biological drug which modifies the course of the disease. The treatment should be modified until the therapeutic goal is reached [8], and only then may it be continued. Effectiveness of biological drugs in reaching this goal is $24.2 \%$ for etanercept monotherapy and $49.4 \%$ for etanercept with methotrexate [9], 26\% for adalimumab monotherapy and $43 \%$ in combination with methotrexate, $33 \%$ (in week 52 ) for the combination of infliximab with methotrexate [10] and $20 \%$ for the combi- nation of rituximab with methotrexate [11]. The analysis of data shows that most therapies are continued for a period exceeding 1 year, which is in contravention of the new EULAR recommendations. The recommendations clearly state that the therapeutic goal should be achieved within 6 months or the type of therapy should be changed, which leads to the conclusion that $50-70 \%$ of patients should have their therapy changed earlier than after 1 year (after the first 6 months).

\section{Conflict of interest}

The authors declare no conflict of interest.

\section{References}

1. Silman AJ, Hochberg MC. Epidemiology of the rheumatic diseases, rheumatoid arthritis. Oxford Univerity Press, New York 2001; 31-71.

2. Iltchev P, Śliwczyński A, Czeleko T, et al. Rheumatoid arthritis morbidity rate in Poland in the years 2008-2012 in rural and urban areas. Ann Agricult Envirom Med Lublin 2016; 23,2 (in print).

3. Filipowicz-Sosnowska A, Stanisławska-Biernat E, Zubrzycka-Sienkiewicz A. Rheumatoid arthritis [Polish]. Reumatologia 2004; 42 (Suppl.): 8-13.

4. Aletaha D, Neogi T, Silman AJ, et al. 2010 rheumatoid arthritis classification criteria: an American College of Rheumatology/European League Against Rheumatism collaborative initiative. Ann Rheum Dis 2010; 69: 1580-8.

5. Lis K, Kuzawińska O, Bałkowiec-Iskra E. Tumor necrosis factor inhibitors - state of knowledge. Arch Med Sci 2014; 10: 1175-85.

6. National Institute for Clinical Excellence. Guidance on the use of etanercept and infliximab for the treatment of rheumatoid arthritis, Technology Appraisal No 36, March 2002.

7. Description of drug programs - appendix B33 in http:// www.mz.gov.pl/leki/refundacja/lista-lekow-refundowanych-obwieszczenia-ministra-zdrowia, accessed on 26.10.2015.

8. Smolen J, Landewé R, Breedveld F, et al. EULAR recommendations for the management of rheumatoid arthritis with synthetic and biological disease-modifying antirheumatic drugs: 2013 update. Ann Rheum Dis 2014; 73: 492-509.

9. Klareskog L, van der Heijde D, de Jager JP, et al.; TEMPO (Trial of Etanercept and Methotrexate with Radiographic Patient Outcomes) study investigators. Therapeutic effect of the combination of etanercept and methotrexate compared with each treatment alone in patients with rheumatoid arthritis: double-blind randomised controlled trial. Lancet 2004; 363: 675-81.

10. St Clair EW, van de Heijde D, Smolen JS, et al.: Active-Controlled Study of Patients Receiving Infliximab for the Treatment of Rheumatoid Arthritis of Early Onset Study Group. Combination of infliximab and methotrexate therapy for early rheumatoid arthritis. Arthritis Rheum 2004; 50: 3432-43.

11. Emery P, Fleischmann R, Filipowicz-Sosnowska A, et al. The efficacy and safety of rituximab in patients with active rheumatoid arthritis despite methotrexate treatment. Arthritis Rheum 2006; 54: 1390-14. 